\title{
Preparation of Calibration Solutions
}

\author{
Lane C. Sander and Michele M. Schantz \\ National Institute of Standards and Technology, \\ Gaithersburg, MD 20899, USA \\ lane.sander@nist.gov \\ michele.schantz@nist.gov
}

Video DOI: http://doi.org/10.18434/T4DK5T

Key words: balance; calibrant; calibration; gravimetry; weighing liquids; weighing solids.

Accepted: December 1, 2016

Published: January 12, 2017

https://doi.org/10.6028/jres.122.009

\section{Summary}

Calibration solutions provide the basis for quantitation for most instrumental techniques. The instrumental responses for analytes in calibrants of known composition are compared with corresponding responses in samples to provide quantitation of the constituents. Calibration solutions are used for external standard, internal standard, and standard addition approaches to quantitation. Calibrants can be prepared gravimetrically using reference standards or reference materials of known purity; however, volumetric or other fraction basis is also possible. Calibrants are usually prepared with pure solvents, but the use of natural or other complex matrix materials such as biological fluids is also possible. For such cases, the materials must be well characterized to assure the absence of matrix interferences. This presentation will demonstrate gravimetric preparation of solution calibrants with solid and liquid constituents. Details are described for special requirements employed with the certification of Standard Reference Materials. ${ }^{1}$

\footnotetext{
${ }^{1}$ Contribution of the National Institute of Standards and Technology. Not subject to copyright. Certain commercial equipment, instruments, or materials are identified to specify adequately the experimental procedure. Such identification does not imply recommendation or endorsement by the National Institute of Standards and Technology, nor does it imply that the materials or equipment identified are the best available for the purpose.
} 